\title{
Supply Chain Design by Integrating Multicriteria Decision Analysis and a Sustainability Approach
}

\author{
A. Petrillo**, O. Cooper*, F. De Felice** \\ * Joseph M. Katz Graduate School of Business and College of Business Administration - University of Pittsburgh (PA), \\ Mervis Hall Pittsburgh, Pennsylvania, 15260 USA \\ ** Department of Mechanism, Structures and Environment - University of Cassino,03043 Cassino (FR) ITALY
}

\begin{abstract}
The rising interest in embedding environmental practices into operations management has reshaped supply chain management research and practice into a new landscape. Considerations must be made with respect to the entire supply chain from the production, consumption, and customer service stages to the post-disposal disposition of products. This comprehensive focus has led to the revolution of Green Supply Chain Management. The aim of the present work is to propose a systematic approach that a firm may use to evaluate its own supply chain environmental performances. The approach integrates index methods for Environmental Performance Evaluation (EPE) and Life Cycle Assessment (LCA) with a multi-criteria model based on the Analytic Network Process (ANP) and BOCR Analysis (Benefits, Opportunities, Costs and Risks). A key aspect of the model is the consideration of environmental directives such as the Waste Electrical and Electronic Equipment and the Restriction of the use of certain Hazardous Substances to evaluate and prioritize which green initiatives with respect to environmental performance.
\end{abstract}

Keywords: ANP, BOCR Analysis, Green Supply Chain, WEEE, EPE.

\section{INTRODUCTION}

The consideration of environmental issues has a tremendous impact on the development and operations of a supply chain. However, green supply chain management (GSCM) is an emerging research area, thus there are limited conceptual models on this important subject. In particular the number of models that consider the effect of environmental directives (ED) on greening a supply chain. In consideration of the significance of ED on the performance of a supply chain, this work develops a conceptual model for the successful greening of a supply chain that also takes into consideration environmental directives such as Waste Electrical and Electronic Equipment (WEEE) and Restriction of the use of certain Hazardous Substances (RoHS). Various similar terminologies have emerged to describe GSCM. Some authors (Handfield et al., 2005) state that environmental supply chain management consists of the purchasing function's involvement in activities that include reduction, recycling, reuse and the substitution of materials. More widely they define GSCM as the formal system that integrates strategic, functional and operational procedures and processes for employee training and for monitoring, and summarising and reporting environmental supply chain management information to stakeholders of the firm.

A crucial aspect of a GSCM is the integration of the operational procedures and processes of Reverse Supply Chain Management (RSCM). The main goal of RSCM is to accommodate two-way material flows across the supply chain in order to provide products with opportunities for reuse and recycling (Kocabasoglu et al., 2007). According to the US Council of Logistics Management (Sarkis, 2001), RSCM should encompass two flows. The first is a divergent flow, known as an open-loop system, using traditional SCM skills. The other is a convergent flow, or a closed-loop system; which is a backward linkage that processes all end-of-life products throughout the entire supply chain from end-customers to the original suppliers. The basic driving forces behind RSCM are the increasing pressure from the public for eco-friendly products, the potential financial returns from reuse, recycling, and recovering materials, and the requirements from environmental regulations such as the Waste Electrical and Electronic Equipment (WEEE) (Lysons and Gillingham, 2003; Eckerth, 2004). While reverse logistics in and of itself is becoming increasingly important in the context of analyzing the waste accumulation on the downstream supply chain (Prahinski and Kocabasoglu, 2006, Sundarakani et al., 2010; Hua et al., 2011), RCSM is a really a sub-set of GSCM. Although GSCM enables the maximization of the value of residual assets, attention should be drawn to the challenges which arise from managing the reverse supply chain activities, the inter-firm relationships, and/or the cross-functional supply chain activities.

The present work proposes a multi-criteria based approach for supporting environmental sustainability analysis of the entire supply chain. The approach is based on the integration of Environmental Performance Evaluation (EPE) with a multi-criteria tool based on the well known Analytic Network Process (ANP) methodology and a BOCR Analysis (Benefits, Opportunities, Costs and Risks). The aim of our work is to develop the ANP/BOCR model through the definition of EPE to identify significant factors on environmental aspects; in this way, the ANP/BOCR model could supply valuable information about critical factors/areas throughout the whole supply chain in order to reduce its environmental impact. This study focuses on the supply chain of a typical cathode ray tube of computers (and televisions).

The paper is organized as follows: in section 2, a brief review about the policies and legislation on Waste Electrical and Electronic Equipment is described; section 3, the theory and conceptual model is explained. Then, in section 4, the proposed approach is applied in a specific case study. Finally in section 5 conclusions and results are analyzed. 


\section{A. Petrillo, O. Cooper, F. De Felice / IOSR Journal of Engineering (IOSRJEN) \\ www.iosrjen.org}

Vol. 1, Issue 1, pp. 091-105

\section{DIRECTIVE 2002/95/EC AND DIRECTIVE 2002/96/EC: ROHS \& WEEE}

The useful life of consumer electronic products is relatively short, and decreasing as a result of rapid changes in equipment features and capabilities (Kang and Schoenung, 2004). The growing importance of Information and Communications Technology (ICT) to the world economy has brought about a surge in demand for electronic equipment (Macauley et al., 2001). Waste from electrical and electronic equipment, EEE (WEEE) is one of the highest priority streams in waste management because of its major challenges. Challenges faced by WEEE management are not only consequences of growing quantities of waste but also the complexity of WEEE; it is one of the most complex waste streams because of the wide variety of products from mechanical devices to highly integrated systems and the accelerating technological innovations (Yla-Mella et al., 2004). As a result of the sheer variety of product models, size changes, compatibility issues, etc., the recovery of WEEE is very challenging (Kumar et al., 2005). WEEE has also become an issue of concern to solid waste management professionals (Musson et al., 2000).

In the last two decades, there has been an increase in the number of environmental policies and legislation focusing on the product development process with an effort to reduce the harmful environmental impacts of the products throughout their entire lifecycle; from the product design to manufacturing to consumption and then the eventual end-of-life (EoL) management.

These policies and legislation are almost all based on the principles of extended producer and entire supply chain responsibility. This concept has become an established principle of environmental policy in many countries. This approach integrates sustainable development principles into international trade based on an international environmental law principle known as the "Polluter Pays Principle" (Kibert, 2004).

The European Union (EU) is primarily responsible for setting the green product regulations. One of the most profound examples is the establishment in 2002, of two environmental directives: directive 2002/95/EC on restriction of the use of certain hazardous substances (RoHS) in electrical and electronic equipment (European Parliament, 2003b); and directive 2002/96/EC on waste electrical and electronic equipment (WEEE), respectively (European Parliament, 2003a). Directive RoHS is a legal requirement that bans the use of Lead, Mercury, Cadmium, Hexavalent Chromium (Chromium VI), Polybrominated Biphenyl (PBB), and Polybrominated Diphenyl Ether (PBDE).Directive WEEE introduces the producers' responsibilities, such as increasing the recycling and recovery rate of waste from electric and electronic equipment.

The aims of these two directives are not merely at limiting the use of harmful substances, but they also permeate into the recovery of the harmful substances by requiring recovery rates of at least $70-80 \%$ at the end of their useful life for electrical and electronic equipment in the EU market. This includes products such as PCs, laptops, printers, scanners and other related products.

Sustaining a green supply chain requires a joint collaboration between suppliers including ODM (Original Design Manufacturers)/OEM (Original Equipment Manufacturers) and brand companies. In addition, the organization of manufacturing networks must take product recovery into consideration (Francas and Minner, 2009). Reverse logistics also need to be carefully designed and embedded in the supply chain network (Srivastava, 2008) in order to be successful.

\section{CONCEPTUAL MODEL AND THEORY}

While our understanding of a green supply chain has been expanded there is still a great deal of latitude in how it is defined. Currently, there is an imbalanced scenario within the research, which when considered together provides synergies and contradictions at the same time. The green supply chain could be viewed as a system, with interlocking elements or sub-systems (suppliers and customers), that aims to minimize wastes in the supply chain. Practices and changes within the sub-system(s) will have direct and indirect effects on the subsequent sub-system(s).

It is very difficult for a company to guarantee a complete environmental directive compliant component and manufacturing flow due to the limited capabilities and influence within the entire supply chain. The alternative strategy is to combine the operational strategy of the whole product supply chain to ensure the overall capabilities match the environmental requests, some examples include: new green products design and development, environmental performance assessment, green purchasing, eco-friendly materials, green $\mathrm{SCM}$, environmental information management system, and recycling of end-of-life products.

The aim of our work is to incorporate these considerations into a strategic decision framework for GSCM. This approach highlights the components and elements for GSCM and how they serve as a foundation for the decision framework. Next, we analyze the theoretical background of Analytic Network Process and its application in the conceptual model.

\subsection{Analytic Network Process - ANP: Theoretical background}

The Analytic Network Process (ANP) is the successor of the popular Analytic Hierarchy Process (AHP) model developed by Saaty (1980). The AHP is a Multi-Criteria Decision Making (MCDM) tool at the core of which lies a method for converting subjective assessments of relative importance to a set of overall scores or weights. The AHP is a top-down decision model and, therefore, the criteria and alternatives are assumed independent. However, bias could occur when the criteria and subcriteria are correlated with each other. Fifteen years after the publication of pioneering work in the field of AHP, Saaty $(1980,1996)$ developed the ANP model, which could handle this situation of inner dependence among elements in a network.

Details on the Analytic Network Process (ANP) model can be found in Saaty (1999); the fundamentals are summarized here for completeness. An ANP model consists of the control hierarchies, clusters, elements, interrelationships between elements, and interrelationships between clusters. The modeling process is better understood by dividing it into several steps which are described as follows:

Step 1: Pairwise comparison and relative weight estimation. Pairwise comparisons of the elements in each level are conducted with respect to their relative importance towards their control criterion based on the principle of AHP. Saaty (1980) suggested a scale of 19 when comparing two components (see Table 1). 


\section{A. Petrillo, O. Cooper, F. De Felice / IOSR Journal of Engineering (IOSRJEN) \\ www.iosrjen.org}

Vol. 1, Issue 1, pp. 091-105

Table 1: Semantics scale of Saaty

\begin{tabular}{|l|l|l|}
\hline \multicolumn{1}{|c|}{$\begin{array}{c}\text { Intensity of } \\
\text { importance } \mathbf{a}_{\mathbf{i j}}\end{array}$} & \multicolumn{1}{|c|}{ Definition } & \multicolumn{1}{c|}{ Explanation } \\
\hline 1 & Equal Importance & Two activities contribute equally to the objective \\
\hline 3 & Moderate importance & $\begin{array}{l}\text { Experience and judgment slightly favor one } \\
\text { activity over another }\end{array}$ \\
\hline 5 & Strong importance & $\begin{array}{l}\text { Experience and judgment strongly favor one } \\
\text { activity over another }\end{array}$ \\
\hline 9 & Very strong or demonstrated importance & $\begin{array}{l}\text { An activity is favored very strongly over another; } \\
\text { its dominance demonstrated in practice }\end{array}$ \\
\hline $2,4,6,8$ & Extreme importance & $\begin{array}{l}\text { The evidence favoring one activity over another is } \\
\text { of the highest possible order of affirmation }\end{array}$ \\
\hline & For compromise between the above values & $\begin{array}{l}\text { Sometimes one needs to interpolate a compromise } \\
\text { judgment numerically because there is no good } \\
\text { word to describe it }\end{array}$ \\
\hline
\end{tabular}

The result of the comparison is the so-called dominance coefficient aij that represents the relative importance of the component on row (i) over the component on column (j), i.e., aij=wi / wj. The pairwise comparisons can be represented in the form of a matrix (Saaty, 2007). The score of 1 represents equal importance of two components and 9 represents extreme importance of the component i over the component $\mathrm{j}$.

After all pairwise comparisons are completed the priority weight vector $(w)$ is computed as the unique solution of $A w=\lambda_{\max } \mathrm{w}$, where $\lambda_{\max }$ is the largest eigenvalue of matrix A. Matrix A is defined as:

$$
\mathrm{A}=\left[\begin{array}{ccc}
W 1 / W 1 & \cdots & W 1 / W n \\
\vdots & \ddots & \vdots \\
W n / W 1 & \cdots & W n / W n
\end{array}\right]=\left[\begin{array}{ccc}
1 & \cdots & a 1 n \\
\vdots & \ddots & \vdots \\
1 / a 1 n & \cdots & 1
\end{array}\right]
$$

Step 2: Consistency index estimation. To more accurately represent judgments the comparisons need not be entirely consistent. However, if a set of comparisons are too inconsistent one could just as well have used random entries and the information from the comparisons would not be useful. In order to provide a balance the consistency index (CI) of the derived weights could then be calculated by: $\mathrm{CI}=(\lambda \max -n) \mathrm{n}-1$. In general, if $\mathrm{CI}$ is less than 0.10 , one may be satisfied with the judgments that were derived (Saaty, 2005).

Step 3: Formation of the initial supermatrix. Elements in ANP are the entities in the system that interact with each other. The determination of relative weights mentioned above is based on pairwise comparisons as in the standard AHP. The weights are then put into the supermatrix that represents the interrelationships of elements in the system. The general form of the supermatrix is described here below where $\mathrm{CN}$ denotes the $\mathrm{N}^{\text {th }}$ cluster, $\mathrm{e}_{\mathrm{Nn}}$ denotes the nth element in the $\mathrm{N}^{\text {th }}$ cluster, and $\mathrm{W}_{\mathrm{ij}}$ is a block matrix consisting of priority weight vectors $(w)$ of the influence of the elements in the $\mathrm{i}^{\text {th }}$ cluster with respect to the $\mathrm{j}^{\text {th }}$ cluster.

\begin{tabular}{|c|c|c|c|c|c|c|c|c|c|c|c|c|c|c|}
\hline & \multicolumn{4}{|c|}{$\mathrm{C}_{1}$} & \multicolumn{4}{|c|}{$\mathrm{C}_{2}$} & \multirow[t]{2}{*}{$\ldots$} & \multicolumn{4}{|c|}{$C_{N}$} \\
\hline & & $\mathrm{e}_{11}$ & $\mathrm{e}_{12}$ & $\ldots$ & $\mathrm{e}_{1 \mathrm{n}}$ & $\mathrm{e}_{21}$ & $\mathrm{e}_{22}$ & $\ldots$ & $e_{2 n}$ & & $\mathrm{e}_{\mathrm{N} 1}$ & $\mathrm{e}_{\mathrm{N} 2}$ & $\ldots$ & $\mathrm{e}_{\mathrm{Nn}}$ \\
\hline \multirow{4}{*}{$\mathrm{C}_{1}$} & $\mathrm{e}_{11}$ & \multirow{4}{*}{\multicolumn{4}{|c|}{$\mathrm{W}_{11}$}} & \multirow{4}{*}{\multicolumn{4}{|c|}{$\mathrm{W}_{12}$}} & \multirow{4}{*}{$\ldots$} & \multirow{4}{*}{\multicolumn{4}{|c|}{$\mathrm{W}_{1 \mathrm{~N}}$}} \\
\hline & $\mathrm{e}_{12}$ & & & & & & & & & & & & & \\
\hline & $\ldots$ & & & & & & & & & & & & & \\
\hline & $\mathrm{e}_{1 \mathrm{n}}$ & & & & & & & & & & & & & \\
\hline$\ldots$ & $\ldots$ & & & & & & & & & $\ldots$ & & & & \\
\hline \multirow{4}{*}{$C_{N}$} & $\mathrm{e}_{\mathrm{N} 1}$ & \multirow{4}{*}{\multicolumn{4}{|c|}{$\mathrm{W}_{\mathrm{N} 1}$}} & \multirow{4}{*}{\multicolumn{4}{|c|}{$\mathrm{W}_{\mathrm{N} 2}$}} & \multirow{4}{*}{$\cdots$} & \multirow{4}{*}{\multicolumn{4}{|c|}{$\mathrm{W}_{\mathrm{NN}}$}} \\
\hline & $\mathrm{e}_{\mathrm{N} 2}$ & & & & & & & & & & & & & \\
\hline & $\ldots$ & & & & & & & & & & & & & \\
\hline & $\mathrm{e}_{\mathrm{Nn}}$ & & & & & & & & & & & & & \\
\hline
\end{tabular}

Step 4: Formation of weighted supermatrix. The initial or "unweighted" supermatrix consists of several eigenvectors each of which sums to one. The clusters in the initial supermatrix must be weighted and transformed to a matrix in which each of its columns sums to unity. 


\section{A. Petrillo, O. Cooper, F. De Felice / IOSR Journal of Engineering (IOSRJEN) www.iosrjen.org}

\section{Vol. 1, Issue 1, pp. 091-105}

Step 5: Calculation of global priority vectors and weights. In the final step, the weighted supermatrix is raised to limiting power to get the global priority vectors as in Equation (1):

$$
\lim _{n \rightarrow \infty}(W)^{n}
$$

\subsection{Research Conceptual Model}

Approaches for analyzing the environmental sustainability of a supply chain could be classified into two main types: top-down models based on global level analysis and bottom-up models based on performance of individual companies in a supply chain. The first type is essentially based on a Life Cycle Analysis (LCA) approach which allows one to measure sustainability from a system perspective. Life cycle assessment (LCA) is increasingly used as a decision support system that enables the modelling, the evaluation and the comparison of different alternatives of products, processes or supply chains as regards their environmental and sustainable impacts (Boufateh et al. 2011). On the other hand, bottom-up models such as climate change, related fossil energy use, or ISO 14000 guidelines are focused on measuring the environmental performances of a single company (Gerbens-Leenes et al, 2003). Environmental indicators in this category represent an effective approach for managing the supply chain (SC) sustainability level (Tsoulfas and Pappis, 2008). Index methods based on a predefined set of environmental indicators are usually simple and easy to use tools which provide relevant information for Green Supply Chain Management (Henri and Journeault, 2008).

The importance of collaboration and supplier partnership as a value-added strategy is discussed in great detail by Vachon and Klassen (2008). From a more operational point of view, several papers consider an analysis of a parameter which could mainly affect the Environmental Performance Evaluation (EPE) process.

From this point of view the aim of our model is to integrate different techniques: first, index categories are evaluated in order to define a reference model as an environmental reporting system; then, a multi-criteria model, based on Analytic Network Process (ANP), is developed which reflects the priorities of the influences on the supply chain environmental sustainability level. The primary focus is to assess strategic and/or operational alternatives which could improve the environmental sustainability level of a supply chain. The result is a prioritized set of potential alternatives.

The conceptual model developed is presented in Figure 1.

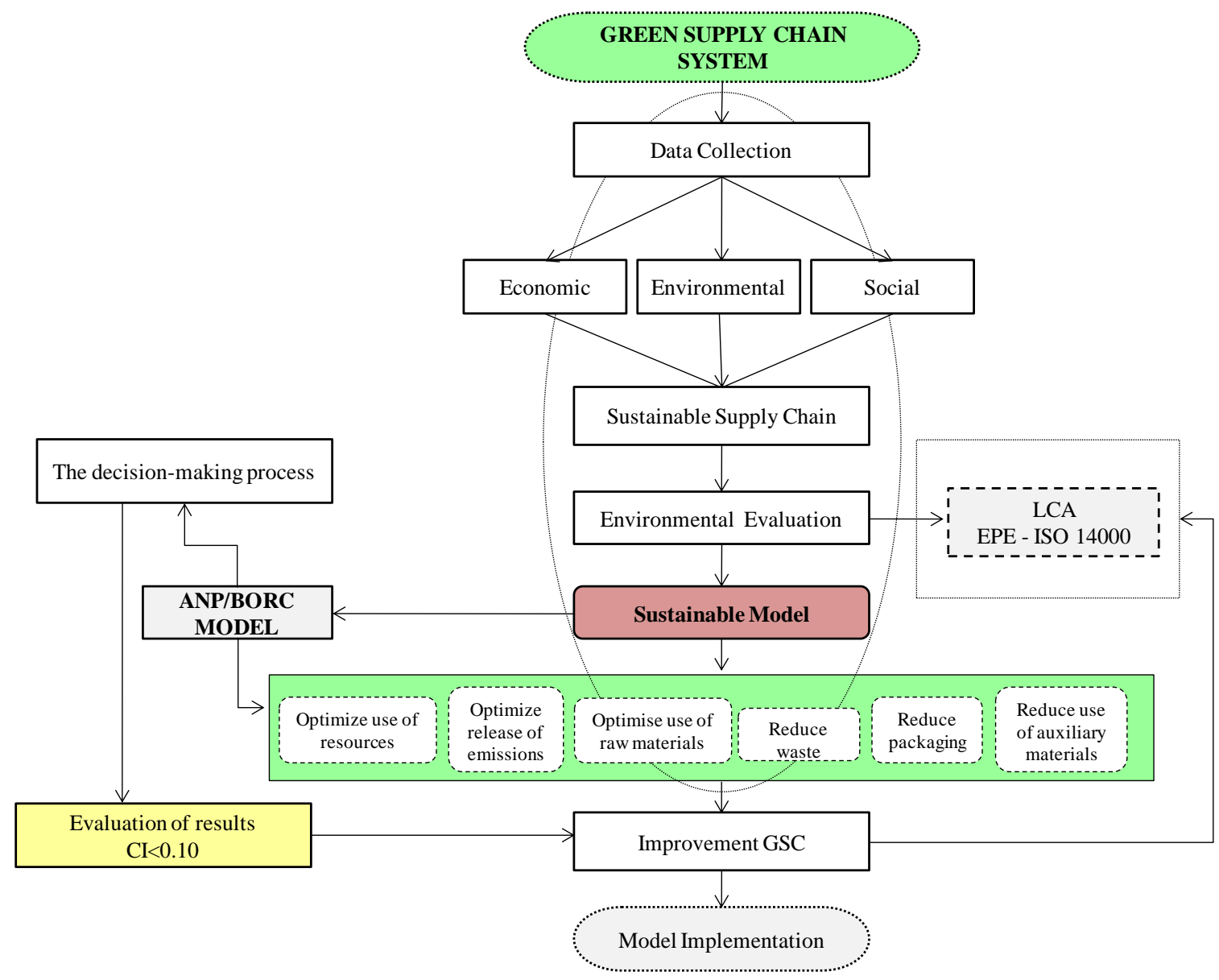

Figure 1: Conceptual model 


\section{A. Petrillo, O. Cooper, F. De Felice / IOSR Journal of Engineering (IOSRJEN) \\ www.iosrjen.org}

\section{Vol. 1, Issue 1, pp. 091-105}

The design of an effective measuring method is carried out with the aim is to integrate information derived from operational fields with global level effects. As reported in literature review, the effectiveness of a reporting system is heavily influenced by the specific structure of a supply chain. This preliminary activity represents a focal analysis as it supplies information about processes and procedures at each level of the SC.

According to ISO 14031 (ISO, 1999), three main subcategories are proposed in order to evaluate sustainability of supply chain: the Operational and Management Performance Indicators (OPI - Operational Performance Indicator and MPI - Management Performance Indicator respectively, ECI - Environmental Condition Indicators). The first category refers to aspects regarding facilities and equipment such as energy flows, waste and emissions, etc. The second is focused on the management's efforts to influence process oriented environmental performances and the last provides information about the condition of the environment which may be useful for the implementation of environmental performance evaluation within an organization. These indicators are fundamental to the development of the BOCR multi-criteria decision support system as they point out critical intervention areas for SC environmental sustainability assessment.

\section{THE CASE STUDY: TV \& AUDIO VIDEO SUPPLY CHAIN}

The proposed model is applied in a full scale case study regarding a TV \& AUDIO VIDEO production supply chain (Figure 2). Usually, this sector is a resource intensive sector; thus, TV \& AUDIO VIDEO manufacturers and processors are under ongoing pressure to maximise efficiency in all areas of production. Supply chain management in this context is a complicated due to the particular nature of the product: bulky, fragile, and difficult to deliver intact while meeting stringent requirements for high quality and safety.

The supply chain structure is quite linear; it consists of a company which produces TV \& AUDIO VIDEO products, with a low number of first-tier suppliers and several intermediate customers (i.e. the final product is an intermediate material for different applications). A schema is proposed in Figure 2 which highlights the main parameters that influence its environmental sustainability level.

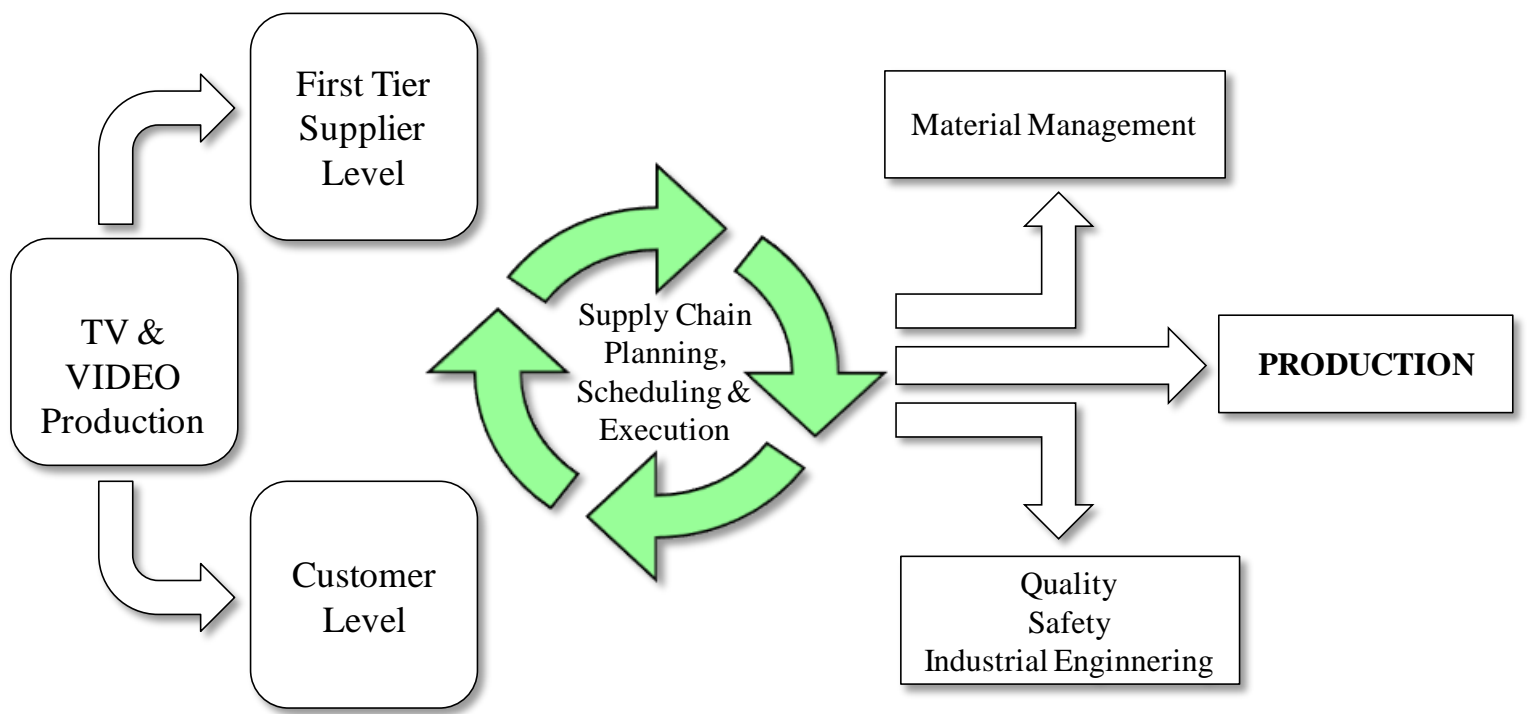

Figure 2. The TV \& AUDIO VIDEO supply chain schema

The proposed model has been applied to evaluate the SC environmental sustainability level and areas where intervention must have priority. Whenever possible the SC structure has been analyzed by applying the metrics system from the EPE process.

\subsection{Collection and aggregation of information}

To collect the information we used the database made available by the company and with information from managers in the areas of interest (see Table 2, 3, 4 and 5). This data is used to provide weightings in the model under these criteria which is explained in greater detail below. 


\section{A. Petrillo, O. Cooper, F. De Felice / IOSR Journal of Engineering (IOSRJEN) \\ www.iosrjen.org}

Vol. 1, Issue 1, pp. 091-105

Table 2. Consumption data

\begin{tabular}{|l|l|}
\hline Description & Unit/total \\
\hline Production & $66,273.31$ ton \\
\hline Electric Energy & $53.499,67 \mathrm{MWh}$ \\
\hline Cogeneration Electric Energy & $71.395,00 \mathrm{MWh}$ \\
\hline Thermic Electric Energy & $80.319,38 \mathrm{MWh}$ \\
\hline Natural Gas Consumption & $10.896 .127,84 \mathrm{Nm}^{3}$ \\
\hline Water Consumption & $1,892,000.0 \mathrm{~m} 3$ \\
\hline $\mathrm{CO}_{2}$ emissions Consumption per unit & $1.3 \mathrm{Ton}$ per ton produced \\
\hline $\begin{array}{l}\text { Auxiliary materials (sodium hydroxide for the } \\
\text { production of demineralized water) }\end{array}$ & $855.700 \mathrm{~kg}$ \\
\hline Raw materials & $80.000 \mathrm{~kg}$ \\
\hline
\end{tabular}

Table 3. Waste data

\begin{tabular}{|l|l|}
\hline Description & Unit/total \\
\hline Hazardous Waste & $8,800 \mathrm{~kg}$ \\
\hline Other wastes & $665,135 \mathrm{~kg}$ \\
\hline Waste & $5,469,336 \mathrm{~kg}$ \\
\hline
\end{tabular}

Table 4. Packaging data

\begin{tabular}{|l|l|}
\hline Description & Unit/total \\
\hline Paper and carton packaging & $3674816 \mathrm{~kg}$ \\
\hline Plastic packaging & $57644.5 \mathrm{~kg}$ \\
\hline Wood packaging & $1282278 \mathrm{~kg}$ \\
\hline Iron packaging & $8900 \mathrm{~kg}$ \\
\hline
\end{tabular}

Table 5. LCA data

\begin{tabular}{|l|l|}
\hline Description & Unit/total \\
\hline Acidification & $6.55 \mathrm{~g} \mathrm{SO}_{2} / \mathrm{kg}$ products \\
\hline GWP 100 & $0.855 \mathrm{~kg} \mathrm{CO}_{2}$ eq $/ \mathrm{kg}$ product \\
\hline Ecotoxitcity & $14.2 \mathrm{cgPb}$ eq $/ \mathrm{kg}$ product \\
\hline
\end{tabular}

\subsection{ANP/BOCR model}

In this section we analyze ANP/BOCR Model and its elements.

The process of developing an ANP/BOCR model follows these practical steps:

1. Structure the problem with respect to its goal;

2. Create the benefits, opportunities, costs and risks networks;

3. Establish control criteria to evaluate the benefits, opportunities, costs, and risks;

4. Define the decision subnets for each control criteria;

5. Complete the pairwise comparisons on cluster elements;

6. Evaluate the rating model to combine the benefits, opportunities, costs, and risks;

7. Synthesize/Combine the model with respect to the strategic criteria;

8. Perform sensitivity analysis to test the stability of the results. 

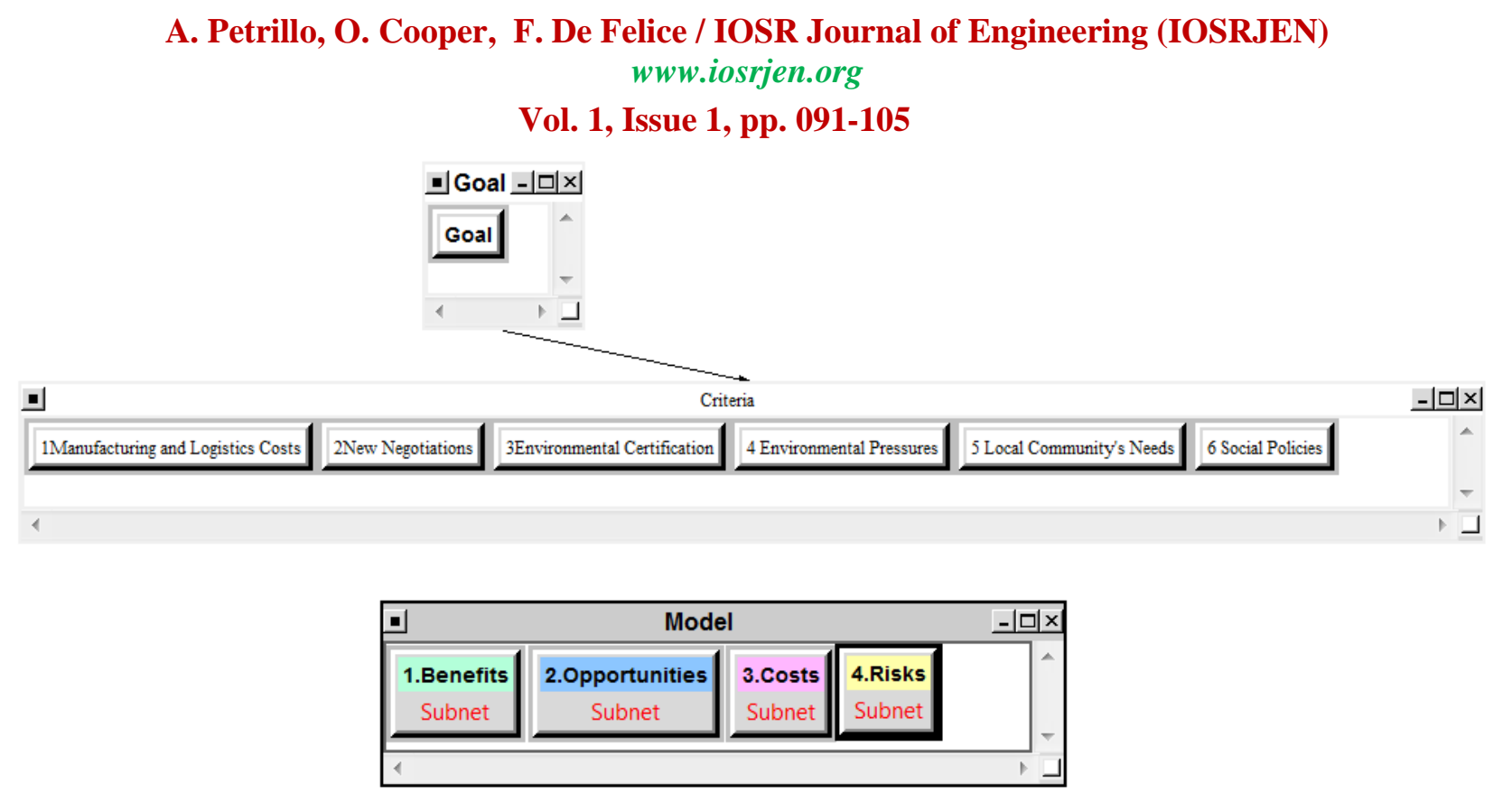

Figure 3. ANP/BOCR Model

The ANP model has been developed by a specific software tool, Super Decisions Software for Decision-Making®.

\subsubsection{Alternatives}

The alternatives cluster is represented by the following specific alternatives (A1) Installation of emission abatement, (A2) Installation of evaporative towers to recycle water, (A3) Installation of solar panels, (A4) Reuse packaging and (A5) Reuse of second hand materials.

\subsubsection{Criteria}

The criteria are described below:

- Manufacturing and Logistics Costs: These encompass the costs throughout the entire supply chain.

- New Negotiations: Changes that come about because of negotiations from other members of the supply chain, e.g. a company demanding a $25 \%$ reduction in packaging.

- Environmental Certification: The need to satisfy the requirements for ISO certification and of legislation, e.g. catalytic converters.

- Environmental Pressures: Similar to environmental certification but for issues that have not been mandated, e.g. hydraulic fracking chemicals.

- Local Community Needs: Requests from the community that are not mandated by law, e.g. noise pollution.

- Social Pressures: When a group or organization push for change within the supply chain. This is especially important for market share considerations, e.g. (coffee and deforestation initiatives).

\subsubsection{BOCR Network}

The strategic criteria and clusters are described below:

\section{Benefits}

Economic

- Advantages: Activities can build value through sustainable methods.

- Sustainable Targets: The evaluation and implementation of actions to reduce environmental impacts.

Social

- Society: Social benefits achieved from the development of sustainability level.

- Individual: Evaluation of actions to improve health care and reduce environmental damage. Environmental

- $\quad$ EPE (MPI-ECI-OPI): Assessment of the status of environmental performance measures.

2. Opportunities

Economic

- Process: Processes associated with planning, scheduling, and coordinating supply chain activities. The effectiveness of an organization in managing assets to support demand satisfaction.

Social 


\section{A. Petrillo, O. Cooper, F. De Felice / IOSR Journal of Engineering (IOSRJEN) \\ www.iosrjen.org}

\section{Vol. 1, Issue 1, pp. 091-105}

- Resources: Processes associated with the development of territory and Human Resources e.g. life long learning.

- Environmental

- Law: Identification and quantification of energy and resource use and environmental releases to air, water, and land according to European or National decrees.

3. Costs

Economic

- Infrastructure: Activities that require economic investment to ensure a green supply chains.

Social

- Human Resources: Activities that require economic investment to ensure safeguard of employees, citizen, etc.

Environmental

- Joint Venture: Agreements with suppliers that define the levels of "sustainability" or resource upside available within state.

\section{Risks}

Economic

- Profitability: Evaluation of the ability to earn a profit.

Social

- Social Risk: Loss of competitiveness

Environmental

- Environmental Risks: Actual or potential threat of adverse effects arising out of the organization's activities.

- LCA - Analysis of inventory: Qualitative and quantitative characterization and assessment of the consequences on the environment.

Here below, in Table 6, 7, 8, 9 and 10 we described a Decision Network and BOCR Analysis control criteria, clusters, elements and alternatives for a general model. Then in last column we pointed out elements for our specific model.

Table 6: Decision Network for BOCR Analysis - Benefits

\begin{tabular}{|c|c|c|c|c|}
\hline \multicolumn{5}{|c|}{ BENEFITS } \\
\hline Model & Control Criteria & Clusters & General Elements & Specific Elements \\
\hline \multirow[t]{5}{*}{ Benefits } & \multirow[t]{2}{*}{ Economic } & Advantages & $\begin{array}{l}\text { Company's value increase } \\
\text { Costs saving } \\
\text { Profitable green } \\
\text { Relation benefits }\end{array}$ & / \\
\hline & & Sustainable Targets & $\begin{array}{l}\text { Optimize use of resources } \\
\text { Optimize use of raw materials } \\
\text { Reduce waste } \\
\text { Reduce use of auxiliary materials } \\
\text { Reduce packaging } \\
\text { Optimize release of emissions }\end{array}$ & l \\
\hline & \multirow[t]{2}{*}{ Social } & Society & $\begin{array}{l}\text { Damage Prevention } \\
\text { Improvement local community's } \\
\text { relationship }\end{array}$ & l \\
\hline & & Individual & $\begin{array}{l}\text { Health care } \\
\text { Damage Reduction } \\
\text { Improvement } \\
\text { relationship }\end{array}$ & / \\
\hline & Environmental & EPE - MPI & $\begin{array}{l}\text { Implementation of policies and } \\
\text { programs } \\
\text { Conformity } \\
\text { Financial performance } \\
\text { Employees performance } \\
\text { Management and planning } \\
\text { Purchases and investments }\end{array}$ & 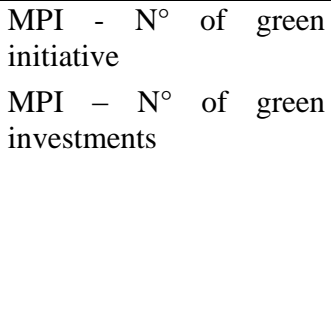 \\
\hline
\end{tabular}


A. Petrillo, O. Cooper, F. De Felice / IOSR Journal of Engineering (IOSRJEN)

www.iosrjen.org

Vol. 1, Issue 1, pp. 091-105

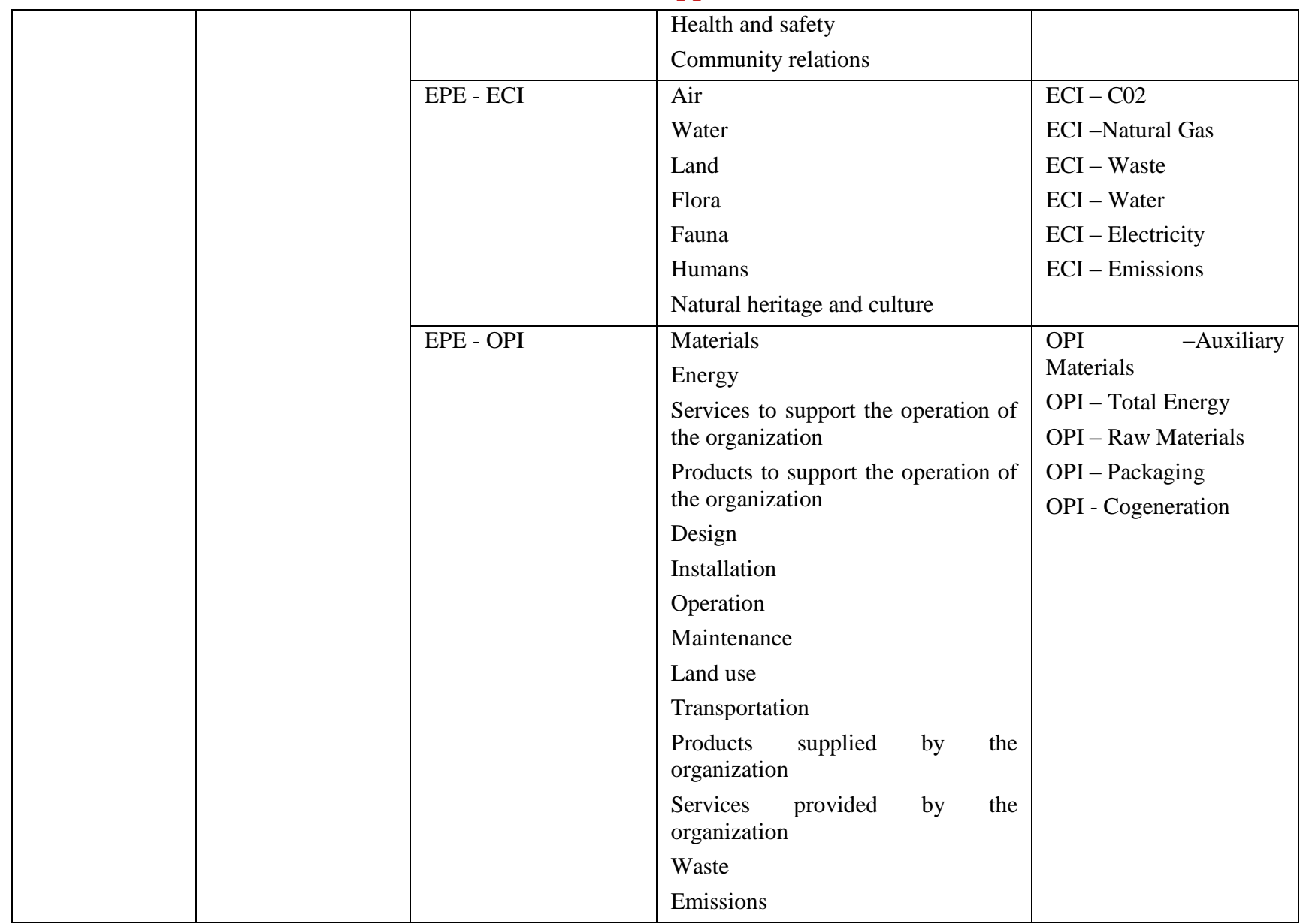

Table 7: Decision Network for BOCR Analysis - Opportunities

\begin{tabular}{|c|c|c|c|c|}
\hline \multicolumn{5}{|c|}{ OPPORTUNITIES } \\
\hline Model & Control Criteria & Clusters & General Elements & Specific Elements \\
\hline \multirow[t]{3}{*}{ Opportunities } & Economic & Process & $\begin{array}{l}\text { Improvement of production process } \\
\text { Customers' satisfaction } \\
\text { Improvement stakeholders' } \\
\text { relationship } \\
\text { Improvement bank's relationship } \\
\text { Adaptability - Be Creative } \\
\text { Development of environmental } \\
\text { economic and social culture }\end{array}$ & l \\
\hline & Social & Resources & $\begin{array}{l}\text { Promotion of territorial identity } \\
\text { Develop new professional skills } \\
\text { Stimulate the establishment of } \\
\text { quality products }\end{array}$ & l \\
\hline & Environmental & Law & $\begin{array}{l}\text { New sustainable regional planning } \\
\text { European/National Policies } \\
\text { enforcement } \\
\text { Sustainable production methods }\end{array}$ & I \\
\hline
\end{tabular}




\section{A. Petrillo, O. Cooper, F. De Felice / IOSR Journal of Engineering (IOSRJEN) \\ www.iosrjen.org}

Vol. 1, Issue 1, pp. 091-105

Table 8: Decision Network for BOCR Analysis - Costs

\begin{tabular}{|l|l|l|l|c|}
\hline \multicolumn{2}{|c|}{ COSTS } \\
\hline Model & Control Criteria & \multicolumn{1}{|c|}{ Clusters } & \multicolumn{1}{c|}{ Elements } & Specific Elements \\
\hline Costs & Economic & Infrastructure & $\begin{array}{l}\text { Increase in infrastructure costs } \\
\text { Increase counseling costs }\end{array}$ & $/$ \\
\cline { 2 - 5 } & Social & Human Resources & $\begin{array}{l}\text { Training costs } \\
\text { Health care survey costs }\end{array}$ & $/$ \\
\cline { 2 - 5 } & Environmental & Joint Venture & Partner skills & $/$ \\
\end{tabular}

Table 9: Decision Network for BOCR Analysis - Risks

\begin{tabular}{|c|c|c|c|c|}
\hline \multicolumn{5}{|c|}{ RISKS } \\
\hline Model & Control Criteria & Clusters & Elements & Specific Elements \\
\hline \multirow[t]{4}{*}{ Risks } & Economic & Profitability & $\begin{array}{l}\text { Net profit Margin } \\
\text { Standardization }\end{array}$ & / \\
\hline & Social & Social Risks & $\begin{array}{l}\text { Legal Penalties } \\
\text { Paternalism } \\
\text { Stigma }\end{array}$ & l \\
\hline & Environmental & Environmental Risks & $\begin{array}{l}\text { Data Collection } \\
\text { Implementation of failure } \\
\text { Introduction of indirect Problems }\end{array}$ & l \\
\hline & & $\begin{array}{lll}\text { LCA }- \text { Analysis } & \text { of } \\
\text { inventory } & & \end{array}$ & $\begin{array}{l}\text { Global warming potential-GWP } \\
\text { Ozone } \\
\text { Consumption of non-renewable } \\
\text { resources } \\
\text { Acidification } \\
\text { Eutrophication } \\
\text { Photochemical smog } \\
\text { Ecotoxicity }\end{array}$ & $\begin{array}{l}\text { Acidification } \\
\text { Global warning } \\
\text { protection } \\
\text { Ecotoxitcity }\end{array}$ \\
\hline
\end{tabular}

Table 10: Decision Network for BOCR Analysis - Alternatives

\begin{tabular}{|c|c|c|c|}
\hline ALTERNATIVES & $\begin{array}{l}\text { ALL } \\
\text { NETWORKS }\end{array}$ & $\begin{array}{ll}\text { 1. } & \mathrm{A} 1 \\
\text { 2. } & \mathrm{A} 2 \\
\text { 3. } & \mathrm{A} 3 \\
\text { 4. } & \ldots . . \\
\text { 5. } & \mathrm{An}\end{array}$ & $\begin{array}{l}\text { 1. Installation of emission abatement } \\
\text { 2. Installation of evaporative towers to allow } \\
\text { recycling of water } \\
\text { 3. Installation of solar panel } \\
\text { 4. Reuse packaging } \\
\text { 5. Reuse of second hand materials }\end{array}$ \\
\hline
\end{tabular}

These criteria were ranked according to the BOCR. The control criteria are used to generate the weights of the BOCR with a ratings model (Figure 4). The following figures (Figure 5, 6 and 7) depict the local priority and overall synthesis according additive and multiplicative formulas. 


\section{A. Petrillo, O. Cooper, F. De Felice / IOSR Journal of Engineering (IOSRJEN) \\ www.iosrjen.org}

Vol. 1, Issue 1, pp. 091-105

\begin{tabular}{|c|c|c|c|c|c|c|c|c|}
\hline 3 Ratings for & Super Deci & Main Window: Co & oper_Petrillo_BOR & RC_Green Suppl & y Chain.sdmod: $f$ & ormulaic: ratings & \begin{tabular}{l|l|l} 
& $\square$ & \\
\end{tabular} & 8 \\
\hline File Edit Vie & w Calcul & Help & & & & & & \\
\hline & & & Super Deci & isions Rati & ings & & & \\
\hline & Priorities & $\begin{array}{l}\text { 1Manufacturing ar } \\
0.114031\end{array}$ & $\begin{array}{l}2 \text { New Negotiation } \\
0.051063\end{array}$ & $\begin{array}{l}3 \text { Environmental C } \\
0.247578\end{array}$ & $\begin{array}{l}\text { C. } 4 \text { Environmental } \\
0.350924\end{array}$ & $\begin{array}{l}5 \text { Local Communit } \\
0.075539\end{array}$ & $\begin{array}{l}6 \text { Social Policies } \\
0.160864\end{array}$ & $\wedge$ \\
\hline 1.Benefits & 0.223210 & MEDIUM & LOW & \begin{tabular}{|l|} 
Level 2 \\
\end{tabular} & MEDIUM-HI & MEDIUM-LOW & MEDIUM-LOW & \\
\hline 2.Opportunities & 0.260958 & MEDIUM & LOW & Level 2 & MEDIUM-HI & MEDIUM-HI & MEDIUM & \\
\hline 3. Costs & 0.310530 & MEDIUM-HI & MEDIUM-LOW & Level 2 & $\mathrm{HI}$ & MEDIUM & MEDIUM & \\
\hline 4.Risks & 0.205301 & LOW & MEDIUM & Level 2 & MEDIUM & LOW & MEDIUM & \\
\hline 4 & & & & & & & & - \\
\hline
\end{tabular}

Figure 4. ANP/BOCR Model
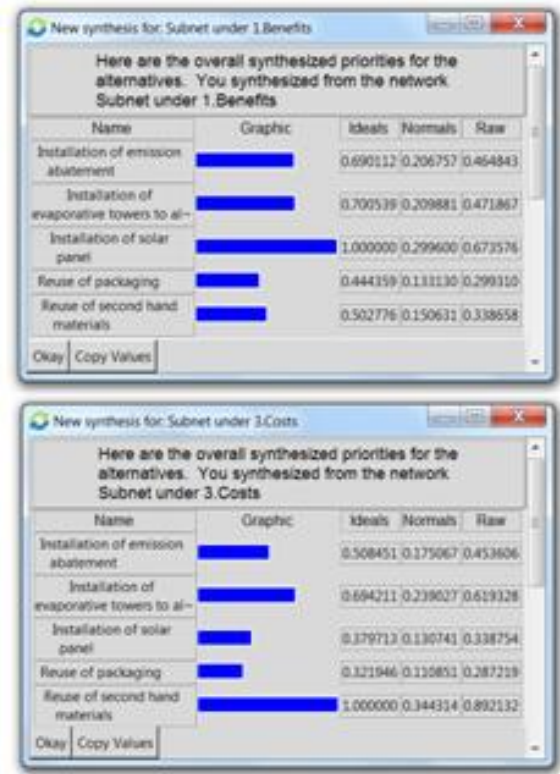
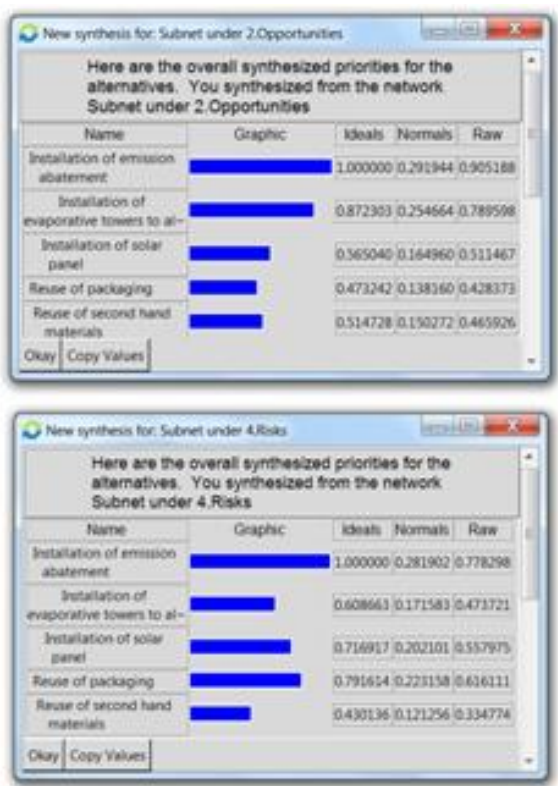

Figure 5. Local Priorities

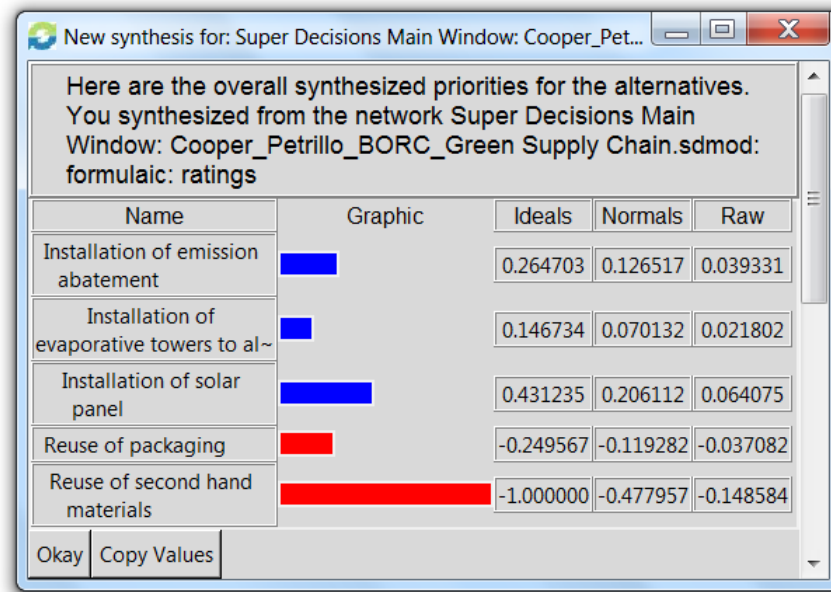

Figure 6. Global Priority - Additive Formula 


\section{A. Petrillo, O. Cooper, F. De Felice / IOSR Journal of Engineering (IOSRJEN) \\ www.iosrjen.org}

Vol. 1, Issue 1, pp. 091-105

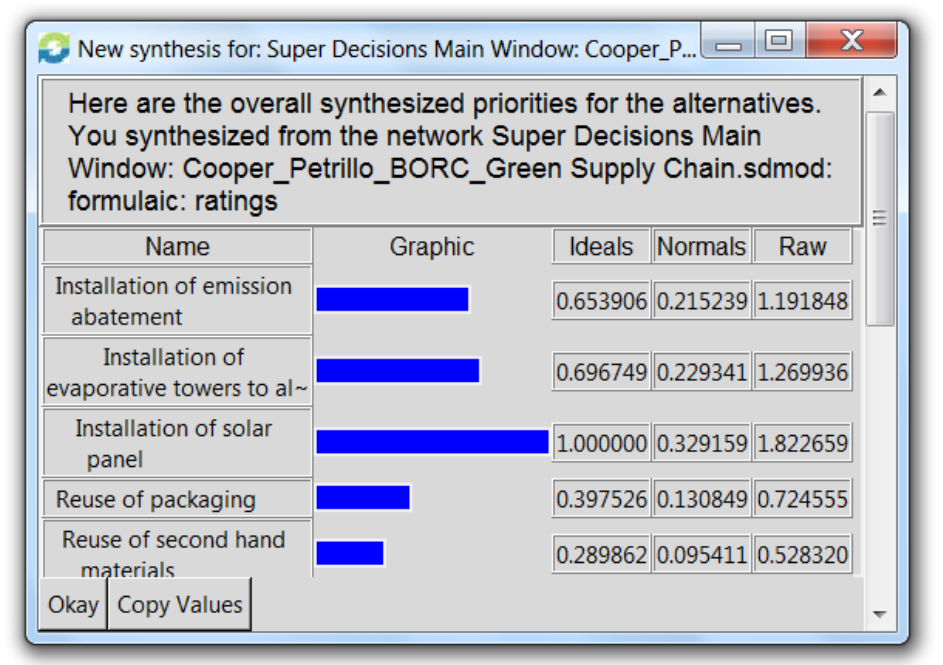

Figure 7. Global Priority - Multiplicative Formula

The alternative to install solar panels is best alternative within the Benefits cluster; for the most opportunities installing the installation equipment if the preferred alternative. The reuse of packaging is the least costly alternative, while the reuse of second hand materials is the least risky. When the model is synthesized in both the short term (multiplicative) and long term (additive) models the best option is to install solar panels. To test the stability of our decision we performed sensitivity analysis (Figure 8 ) to test the robustness of the decision with respect to changes in the weighting of the benefits, opportunities, costs and risks. The following graphs summarize the results:

The graphs below show that for:

1. Benefits, Costs as the independent variable the optimum solution is the installation of solar panel;

2. Opportunities as the independent variable the optimum solution is the installation of emission abatement;

3. Risks as the independent variable the optimum solution is reuse of second hand materials.
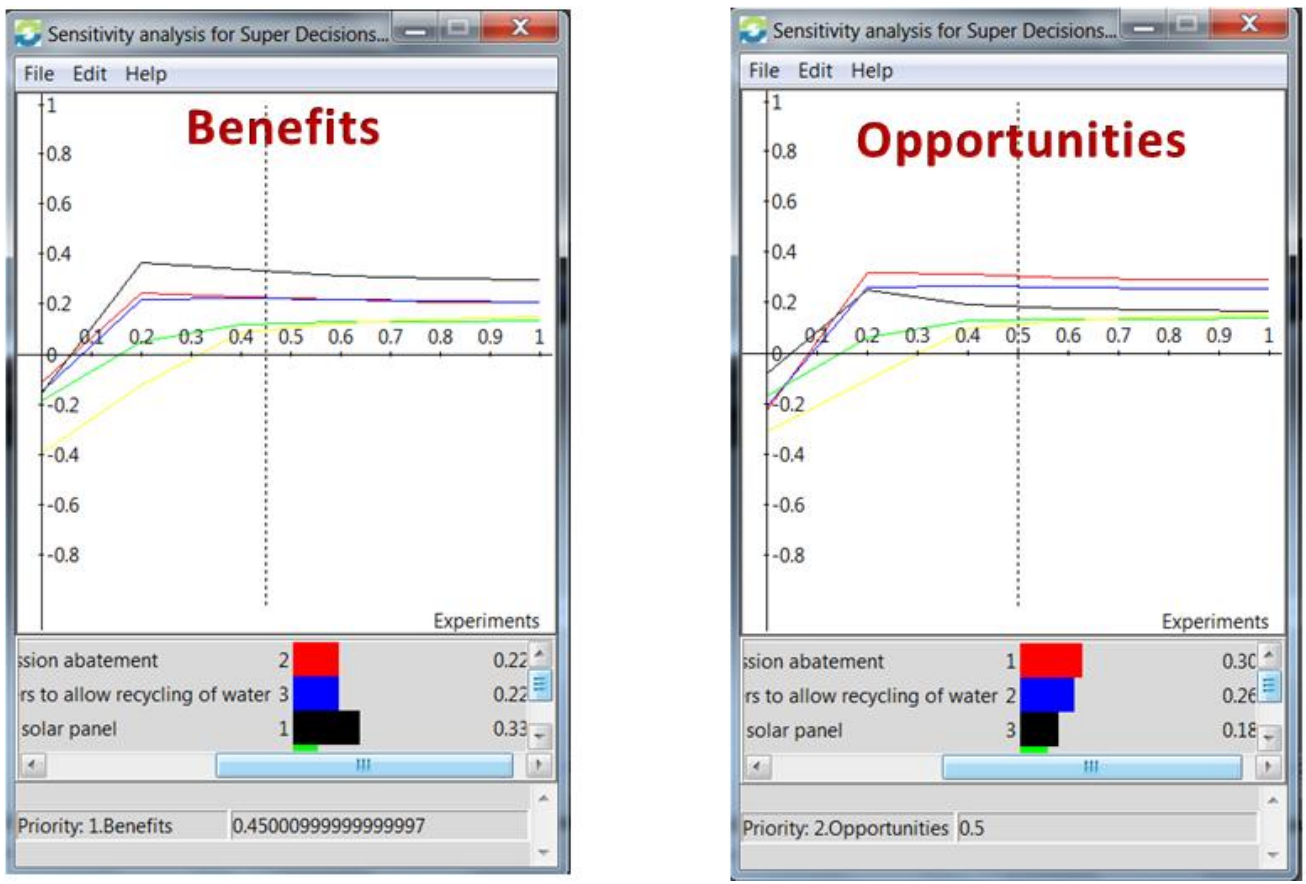


\section{A. Petrillo, O. Cooper, F. De Felice / IOSR Journal of Engineering (IOSRJEN) \\ www.iosrjen.org}

Vol. 1, Issue 1, pp. 091-105
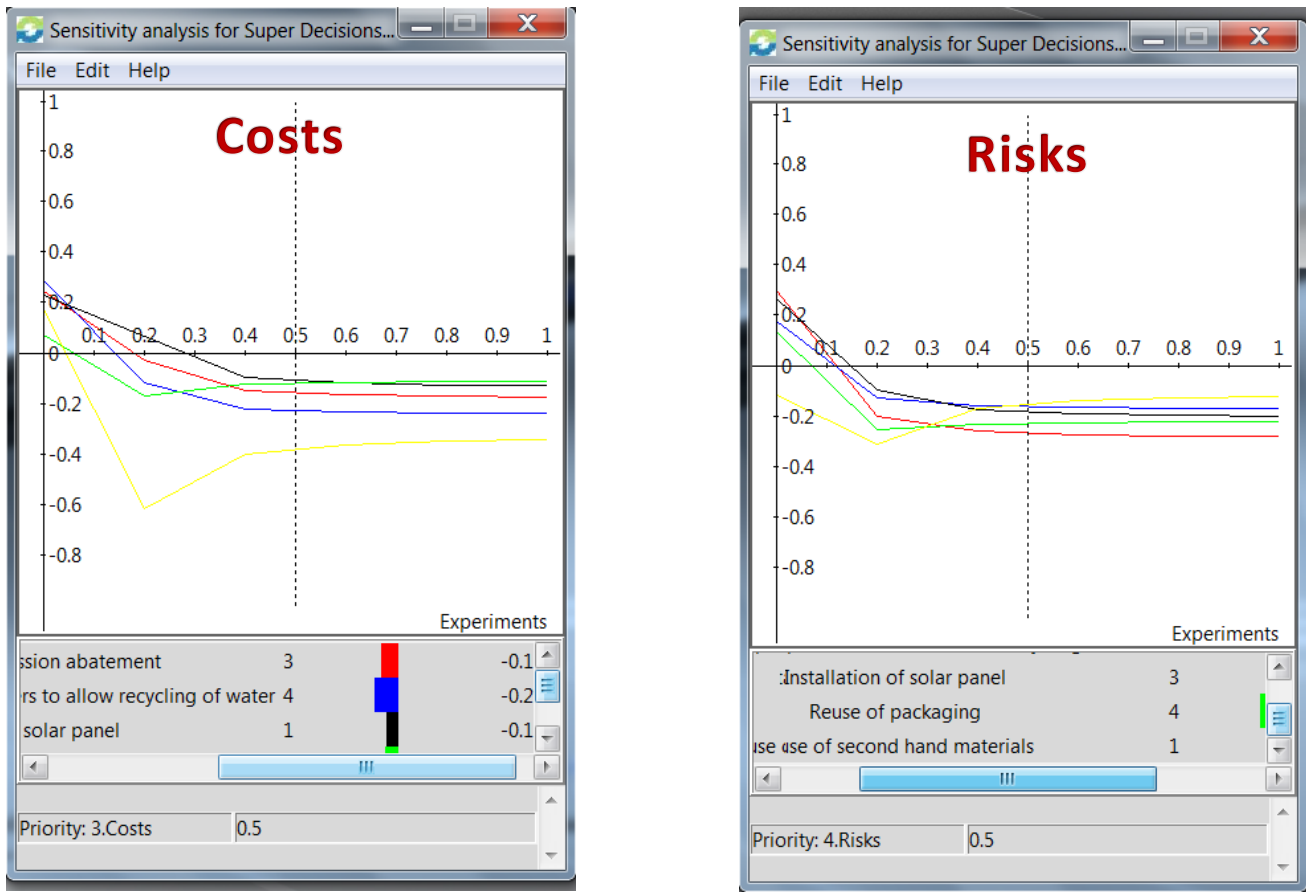

Figure 8. Sensitive Analysis

\section{CONCLUSIONS AND RESULTS}

Based on the results of this model in the specific case study of the TV \& Audio and Video supply chain the manufacturer should install solar panels. The general model and criteria can be adapted and applied to other supply chains and to include different alternatives. The model is an integrated approach to evaluate the environmental sustainability of a supply chain. The proposed approach involves the evaluation of the entire supply chain: the environmental performance of a product or a producer depends not only on its production process, but the whole life cycle has to be evaluated starting from the first supplier to distribution to the final customer and final recovery activities. The approach integrates index methods for Environmental Performance Evaluation (EPE) with a complex multi-criteria model, the Analytic Network Process (ANP). This proposed approach aims to optimize the development of the ANP model through a previous definition of EPE to identify significant factors of environmental aspects; in this way, the ANP model supplies effective information about critical factors/areas in the entire supply chain in order to optimize the sustainability level. The model has been tested in a real supply chain regarding the TV \& AUDIO VIDEO production. This supply chain is characterized by a simple structure as a company heavily influences SC performance; moreover, environmental sustainability is sues are relevant in this SC. Results obtained have highlighted different capabilities. Further developments could be oriented in applying the approach to several industrial fields where SC structure complexity arises.

\section{Acknowledgement}

Antonella Petrillo, degree in Mechanical Engineering, now researcher at the Faculty of Engineering of University of Cassino where she conducts research activities on Multi-criteria decision analysis (MCDA) at the Department of Mechanism, Structures and Environment.

Orrin Cooper, now Phd Student at the University of Pittsburgh - Joseph M. Katz Graduate School of Business where he conducts research activities on Decision Sciences

Fabio De Felice, Professor at the Faculty of Engineering of the University of Cassino, board member of several international organizations and responsible for scientific research and training in industrial plants. Holder of the course planning and management of industrial plants.

The scientific activity developed through studies and researches on problems concerning industrial plant engineering. Such activity ranges over all fields from improvement of quality in productive processes to the simulation of industrial plants, from support multicriteria techniques to decisions (Analytic Hierarchy Process, Analytic Network Process), to RAMS Analysis and Human Reliability Analysis. The main courses, both curricular and specialistic for territorial businesses in which he is involved are: Safety of Industrial Plants, Industrial Production Management, Industrial Simulation, Human Reliability Analysis. General Secretary of the Analytic Hierarchy Process - A.H.P. Academy - International Association for the promotion of multi-criteria decision making methods. 


\section{A. Petrillo, O. Cooper, F. De Felice / IOSR Journal of Engineering (IOSRJEN) \\ www.iosrjen.org}

Vol. 1, Issue 1, pp. 091-105

\section{References:}

Boufateh, I., Perwuelz, A., Rabenasolo, B., Jolly-Desodt, A.M., 2011. Multiple criteria decision-making for environmental impacts optimization. International Journal of Business Performance and Supply Chain Modelling 2011 - Vol. 3 (1) pp. 28 - 42.

Eckerth, G., 2004. Supply chain management in take back of WEEE. In: Proceedings of the Electronics Goes Green, Berlin, Germany, 6-8 September 2004, pp. 241-244.

European Parliament,2003a.Directive 2002/96/EC on Waste Electrical and Electronic Equipment (WEEE), (Online) /http://europa.eu.int/eur-lex/lex/Lex UriServ/LexUriServ.do?uri=CELEX:32002L0095:EN:HTMLS (accessed in10 May, 2005).

European Parliament,2003b.Directive2002/95/EC on the Restriction of the Use of Certain Hazardous Substances in Electrical and Electronic Equipment,(Online), /http://europa.eu.int/eur-lex/lex/LexUriServ/LexUriServ.do?uri=CELEX:32002 L0095:EN:HTMLS (accessed in10May2005).

Francas, D., Minner, S., 2009. Manufacturing network configuration in supply chains with product recovery. OMEGA 37 (4), $757-$ 769.

Gerbens-Leenes PW, Moll HC, Schoot Uiterkamp AJM, (2003), Design and development of a measuring method for environmental sustainability in food production systems, Ecological Economics, Vol.46, pp. 231-248.

Handfield, R., Sroufe, R., Walton, S., 2005. Integrating environmental management and supply chain strategy. Business Strategy and the Environment 14, 1-19.

Henri J, Journeault M, (2008), Environmental performance indicators: An empirical study of Canadian manufacturing firms, Journal of Environmental Management, Vol. 87, pp. 165-176.

Hua, G., Cheng, T.C.E., Wang, S., 2011. Managing carbon footprints in inventory management. International Journal of Production Economics $132(2), 178-185$.

ISO, (1999). Environmental performance evaluation e guidelines- ISO 14031. Geneva: International Standard Organization.

Kang H-Y, Schoenung JM. Used consumer electronics: a comparative analysis of material recycling technologies. In: 2004 IEEE international symposium on electronics and the environment; 2004.

Kibert NC. Extended producer responsibility: a tool for achieving sustainable development. J Land Use Environ Law 2004;19:50323. http://www.law.fsu.edu/journals/landuse/vol19 2/kibert.pdf.

Kocabasoglu, C., Prahinski, C., Klassen, R.D., 2007. Linking forward and reverse supply chain investments: the role of business uncertainty. Journal of Opera- tions Management 25, 1141-1160.

Koh, S.C.L., Gunasekaran, A., Tseng, C.S. (2011). Cross-tier ripple and indirect effects of directives WEEE and RoHS on greening a supply chain. Int. J.ProductionEconomics (article in press).

Kumar V, Bee DJ, Shirodkar PS, Tumkor S, Bettig BP, Sutherland JW. Towards sustainable product and material flow cycles: identifying barriers to achieving product multi-use and zero waste. In: Proceedings of IMECE 2005. 2005 ASME international mechanical engineering congress and exposition; 2005.

Lysons, K., Gillingham, M., 2003. Purchasing and Supply Chain Management, 6th ed. Prentice-Hall, Harlow.

Macauley M, Palmer K, Shih J-S, Cline S, Holsinger H. Modeling the costs and environmental benefits of disposal options for endof-life electronic equipment: the case of used computer monitors. Resources for the Future. Discussion Paper, 10-27 June, 2001.

Musson SE, JangY-C, Townsend TG, Chung I-H. Characterization of lead leachability from cathode ray tubes using the toxicity characterization leaching procedure. Environ Sci Technol 2000;34:4376-81.

Prahinski, C., Kocabasoglu, C., 2006. Empirical research opportunities in reverse supply chain. OMEGA 34 (6), 519-534.

Sarkis, J., 2001. Greener Manufacturing and Operation. Greenleaf Publishing, Sheffield.

Saaty, T.L., 1980. The Analytic Hierarchy Process. John Wiley, New York.

Saaty, T.L., 1996. The Analytic Network Process. RWS Publications, Pittsburgh, PA. 


\section{A. Petrillo, O. Cooper, F. De Felice / IOSR Journal of Engineering (IOSRJEN) \\ www.iosrjen.org}

\section{Vol. 1, Issue 1, pp. 091-105}

Saaty, T.L., 1999. Fundamentals of the analytic network process. Proc of International Symposium on Analytical Hierarchy Process, Kobe, Japan.

Saaty, T.L., 2005. Theory and Applications of the Analytic network Process: decision making with benefits, opportunities, costs, and risks. RWS Publications, (Pittsburg, USA).

Saaty T. L., Peniwati K., 2007. Group Decision Making: Drawing out and Reconciling Differences. RWS Publications, (Pittsburg , USA).

Srivastava, S.K., 2008. Network design for reverse logistics. OMEGA 36 (4), 535-548.

Sundarakani, B., de Souza, R., Goh, M., Wagner, S.M., Manikandan, S., 2010. Modelling carbon footprints across the supply chain. International Journal Production Economics 128 (1), 43-50.

Tsoulfas T, Pappis CP, (2008), A model for supply chains environmental performance analysis and decision making Journal of Cleaner Production, Vol. 16, pp. 1647-1657.

Vachon S, Mao Z, (2008), Linking supply chain strength to sustainable development: a country-level analysis, Journal of Cleaner Production, Vol. 16, pp.1552-1560.

Vereecke A, Muylle S, (2005), Competitive Success Through Supply Chain Management in The Glass Industry, GLASS PROCESSING DAYS. Available at www.gpd.fi

Yla-Mella Y, Pongracz E, Keiski RL. Recovery of waste electrical and electronic Equipment (WEEE) in Finland. In: Pongracz E, editor. Proceedings of the waste minimization and resource use optimization conference, June 10, 2004, Oulu, Finland. p. 83-92. http://www.oulu.fi/resopt/wasmin/ylamella.pdf. 